\title{
Analysis on the Efficiency of Health Care Service Delivery and Influencing Factors in China: A Study Based on DEA-Malmquist Index and Tobit Model
}

\section{Kui Chen}

First Affiliated Hospital of Anhui Medical University

Jun Ye ( $\square$ yjwz87@163.com )

School of Public Health and Management, Wenzhou Medical University.

\section{Research Article}

Keywords: Health care services, data envelopment analysis, Malmquist index, Tobit model, supply, efficiency

Posted Date: December 15th, 2020

DOI: https://doi.org/10.21203/rs.3.rs-123126/v1

License: (c) (i) This work is licensed under a Creative Commons Attribution 4.0 International License. Read Full License 


\section{Analysis on the Efficiency of Health Care Service Delivery and Influencing Factors in}

\section{China: A Study Based on DEA-Malmquist Index and Tobit Model ${ }^{1}$}

\section{Kui Chen" ${ }^{1 \#, ~ J u n ~ Y e ~}{ }^{2 \# *}$}

\section{Abstract}

Objective: To evaluate the changeing trend and influencing factors of medical and health service supply efficiency in 31 provinces of China.

Methods: According to the input-output relevant index data of medical and health service in China from 2009 to 2018, data envelopment analysis- Malmquist(DEA-Malmquist) was used to calculate the total factor productivity, technical efficiency, and technical change. Meanwhile, Tobit model to analyzed the main effective factors of medical and health service supply efficiency in China

Results: In 2018, 21 provinces including Beijing, Shanghai, Zhejiang and Guangdong were effective in DEA of China's medical and health supply efficiency. Jilin, Heilongjiang, Jiangsu and Shandong were weak DEA effective, while Shanxi, Inner Mongolia, Liaoning, Anhui, Fujian and Xinjiang were not DEA effective. From 2009 to 2018, the total factor productivity of China's medical and health service supply has been decreased steadily, which was mainly affected by technological changes. From the perspective of regions, the technical efficiency and pure technical efficiency of medical and health service supply was the highest in the east, followed by the central and the western region. Associate's degree or above, gross regional domestic product, and health care expenditure were significantly associated with the increasing of medical and health service supply efficiency.

\footnotetext{
1 Correspondence:yjwz87@163.com

Full list of author information is available at the end of the article.
} 
Conclusions: According to their own conditions and constraints, all localities should take targeted measures to strengthen the allocation and management level of medical and health resources, promote technological progress, give full play to the role of education and economic development, increase the expenditure on medical and health care, improve the utilization rate of beds, shorten the average hospitalization days, effectively improve the efficiency of medical and health services supply, and better provide health care for people.

Key words: Health care services; data envelopment analysis; Malmquist index; Tobit model; supply; efficiency 


\section{Background}

Health care is a fundamental human right and the basis for the formation of a country's human capital. ${ }^{[1]}$ A high-quality and efficient delivery system for health care services, as a guarantee to meet people's health needs, plays an important role in economic development and social progress. With the continuous improvement of China's health care system, the medical needs of the population are continuously being released both in quantity and quality, showing a diversified trend with increased pressure on the supply of medical services. ${ }^{[2]}$ However, health care service delivery reform is lagging behind, the allocation of health care resources is unreasonable, the supply capacity of health care services is insufficient, and the contradiction of medical services between supply and demand is very prominent. ${ }^{[3]}$ From the perspective of service supply, insufficient medical and health resources coexist with structural imbalance. In terms of efficiency, the shortage and waste of health care resources exist simultaneously. ${ }^{[4]}$ The key to solving this problem is figuring out how to improve the efficiency and performance of health care service delivery under the situation of limited medical resources.

Improving the quality of the health care delivery system in China is inseparable from the two basic issues. One is how to invest more resources into health care and increase the supply, ${ }^{[5]}$ and the other is how to measure the delivery of health care services and improve the efficiency of health care resource allocation. Data envelopment analysis (DEA) is a linear optimization performance analysis method that integrates multidimensional data into a comprehensive index and suggests directions for system improvement, ${ }^{[6]}$ which can evaluate the relative efficiency values of decision-making units based on actual input and output data. 
[7] The Malmquist index model, commonly used in DEA, is mainly used to measure total factor productivity (TFP) across decision-making units over different periods. ${ }^{[8]}$ TFP represents the ratio of the total output of a decision-making unit to the input of all factors. The TFP change index can be represented by the product of technical change (TC) and (technical) efficiency change (EC). Efficiency change can be broken down further into the product of pure technical ECs and the extent of ECs. ${ }^{[9-10]}$ Compared to static analytical models, the Malmquist index model has the advantage of analyzing the dynamic efficiency of a decision-making unit (DMU), and can also analyze changes in efficiency over time, along with their causes.

This study uses the DEA-Malmquist index model to evaluate the dynamic changes in health care service delivery, and introducesthe Tobit model to analyze the influencing factors of the efficiency of health care service delivery in China based on the panel data of input-output related health care service indicators in each provinces in Chinese from 2009 to 2018. Additionally, put forward countermeasures to further improve its efficiency, meet public health needs, and provide references for enriching and developing theoretical research, and improving the practical foundation of health care services efficiency in China.

\section{Data sources and research methods}

\section{Research methods}

\section{DEA-BCC model}

This study uses the DEA method to evaluate the efficiency of health care service delivery. Suppose that the Banker-Charnes-Cooper (BCC) model has multiple DMUs, where $x i j$ is the amount invested in health care in a certain province and $x i j \geq 0, y i j$ is the health care 
80

81

output in a certain province and $y i j \geq 0, \theta$ is the target planning value, $\lambda j$ is the planning decision variable, $\varepsilon$ is the non-Archimedes infinitesimal, and $s-$ and $s+$ are the slack variable vectors. If $\theta=1, s-=0$, and $s+=0$, then the DEA of the DMU is valid. If $\theta<1$, then the DMU is the same as the DEA; thus, the DEA is invalid. If $\theta=1$ and $s-\neq 0$ or $s+\neq 0$, then the DMU is weak and the DEA is valid.

$$
\left\{\begin{array}{c}
\min \left[\theta-\varepsilon\left(\sum_{i=1}^{m} s i^{-}+\sum_{r=1}^{n} s r^{+}\right)\right] \\
\sum_{j=1}^{I} x i j \lambda j+s i^{-}=\theta x i k \\
\sum_{j=1}^{I} y r j \lambda j-s r^{+}=y r k \\
\sum_{j=1}^{I} \lambda j=1 \\
\lambda j, s i^{-}, s r^{+} \geq 0, j=1,2, \cdots, n
\end{array}\right.
$$

\subsubsection{DEA-Malmquist model}

The Malmquist index was developed by the Swedish scholar Malmquist in 1953 to analyze trends in dynamic ECs. In 1982, Caves et al. applied the index to measuring productivity changes and named it the Malmquist productivity index. ${ }^{[1]}$ In 1994, Fare combined the Malmquist index with DEA, resulting in a Malmquist productivity index based on periods $\mathrm{t}$ and $\mathrm{t}+1,{ }^{[12]}$ which is expressed as:

$$
M\left(x^{t+1}, y^{t+1}, x^{t}, y^{t}\right)=\left[\frac{D^{t}\left(x^{t+1} y^{t+1}\right)}{D^{t}\left(x^{t} y^{t}\right)} \times \frac{D^{t+1}\left(x^{t+1}, y^{t+1}\right)}{D^{t+1}\left(x^{t} y^{t}\right)}\right]^{\frac{1}{2}}
$$

Where $\left(\mathrm{x}^{\mathrm{t}}, \mathrm{y}^{\mathrm{t}}\right)$ and $\left(\mathrm{x}^{\mathrm{t}+1}, \mathrm{y}^{\mathrm{t}+1}\right)$ denote the input-output vector of China's health care in period $t$ and $t+1$, respectively. If the Malmquist index is greater than 1 , it indicates increased efficiency; if the Malmquist index is less than 1, it indicates reduced efficiency.

\section{Tobit model}


The Tobit model is a model in which the dependent variable satisfies certain constraints and was formally proposed by famed American economist Tobin in 1958. ${ }^{[13]}$ If the independent variable $Y_{i}$ is censored between 0 and 1 , and $Y_{i}$ is related to the independent variable $\mathrm{X}_{\mathrm{i}}$, then there exists the following linear regression model:

$$
Y_{i}=\beta_{0}+\beta^{T} X_{i}+u_{i}
$$

Where $Y_{i}$ is the restricted dependent variable, $X_{i}$ is the explanatory variable, $\beta^{T}$ is the unknown parameter vector, and $\mathrm{u}_{\mathrm{i}}-\mathrm{N}\left(0, \sigma^{2}\right)$.

\section{Index selection and data sources}

This study is based on the current state of China's health care service delivery. ${ }^{[14-15]}$ Taking into account the rationality and validity of the data, this study measures the efficiency of health care service delivery in the 31 Chinese provinces and municipalities from 2009 to 2018. After considering the significance of health care services, the number of beds in medical institutions, the number of medical and technical personnel, and the total health care expenditure of medical institutions were selected as input indicators. Selected as output indicators were the number of medical institution visits, hospital discharges, patient admissions and surgeries, perinatal mortality, maternal mortality, and incidence of category A and $\mathrm{B}$ infectious diseases. The input and output levels of China's health care services were measured separately, as shown in Table 1.

Pure technical efficiency reflects the ability of health care investments to meet overall requirements and maximize their effectiveness. When the pure technical efficiency value is equal to 1 , the technology is efficient, which indicates that the output of health services has 
been maximized. When the pure technical efficiency value is less than 1 , it is not technically efficient, which indicates that the output of health services has not been maximized. Scale efficiency refers to the magnitude of the effect that optimal allocation of health care resources has on its output. When scale efficiency is equal to 1 , the scale is efficient, and the returns to scale for health care resource inputs are at the optimal point between increasing and decreasing returns to scale. When scale efficiency is less than 1 , the scale is not efficient and health care resources are at increasing or decreasing returns to scale. ${ }^{[16]}$ Overall efficiency is equal to pure technical efficiency multiplied by scale efficiency. When pure technical efficiency is equal to 1 and scale efficiency is equal to 1 , both technical and scale efficiency are achieved, and local health care service delivery is said to be DEA efficient. When pure technical efficiency is equal to 1 or scale efficiency is equal to 1 , either technical or scale efficiency has been achieved, and local health care service delivery is said to have weak DEA efficiency. When pure technical efficiency is less than 1 and scale efficiency is less than 1 , both technical and scale efficiency have not been achieved, and local health care service delivery is said to be not DEA efficient. The Malmquist index reflects the changes in the efficiency of health care service delivery in each province and analyzes the efficiency changes in TFP.

\section{Statistical analysis}

This study uses the Tobit model to analyze the factors influencing the efficiency of health care service delivery to avoid biased and inconsistent errors when using the ordinary least squares (OLS) method. ${ }^{[17]}$ The Tobit model is used to analyze the factors influencing the efficiency of 
health care service delivery in China. STATA 15.1 software was used to perform Tobit analysis, and the DEAP 2.1 software was used for the efficiency analysis of health care service input and output indicators. DEAP 2.1 was also used to explore changes in TFP.

\section{Results}

\section{Static analysis of the efficiency of health care service delivery}

\section{Pure technical efficiency}

In 2009 and 2018, the pure technical efficiency value of China's health care service delivery increased to 0.983 from 0.959 , which is an improvement of $2.50 \%$ and a difference of 0.017 from the production frontier. The 25 provinces that achieved pure technical efficiency in 2018 include Beijing, Tianjin, Shanghai, and Jiangsu, indicating that these provinces' health care investments met the overall requirements and achieved maximum efficiency. Six provinces, namely Shanxi, Inner Mongolia, Liaoning, Anhui, Fujian, and Shandong, had a net pure technical efficiency value of less than 1, with Inner Mongolia having only 0.813 .

\section{Scale efficiency}

Overall, the scale efficiency value of China's health care service delivery increased slightly to 0.982 in 2018 from 0.973 in 2009 . The scale efficiency value was 1 for two years in 15 provinces, including Tianjin, Hebei, Shanghai and Zhejiang, accounting for $48.39 \%$ of China's overall scale efficiency value. The nine provinces of Shanxi, Inner Mongolia, Liaoning, Jilin, Heilongjiang, Jiangsu, Anhui, Shandong, and Xinjiang had low scale 
efficiency values of less than 1 in both years. They accounted for $29.03 \%$ of China's overall scale efficiency value. According to the data from 2018, there were 21 provinces with a scale efficiency value of 1 , all of which had unchanged scale gains, accounting for $67.74 \%$ of overall scale efficiency values. Ten provinces had scale efficiency values of less than 1: Shanxi, Inner Mongolia, Liaoning, Jilin, Heilongjiang, Jiangsu, Anhui, Fujian, Shandong, and Xinjiang. These provinces all showed a trend of decreasing returns to scale except for Xinjiang, which had increasing returns to scale.

\section{Overall efficiency}

In 2018, China's health care delivery efficiency was considered DEA efficient in 21 provinces: Beijing, Tianjin, Hebei, Shanghai, Zhejiang, Jiangxi, Henan, Hubei, Hunan, Guangdong, Guangxi, Hainan, Chongqing, Sichuan, Guizhou, Yunnan, Tibet, Shaanxi, Gansu, Qinghai, and Ningxia. Weak DEA efficiency was found in Jilin, Heilongjiang, Jiangsu, and Shandong, while DEA was not efficient in Shanxi, Inner Mongolia, Liaoning, Anhui, Fujian and Xinjiang. (Table 1)

\section{Dynamic analysis of health care service delivery efficiency}

\section{Changes in China's health care service delivery efficiency between 2009 and 2018}

The TFP change index of health care service delivery from 2009 to 2018 was 0.998 , in other words, there was an average annual decrease of $0.2 \%$, as shown in Table 3 . When broken down, the efficiency change index was 1.004, an average annual increase in technical efficiency of $0.4 \%$. This contributed significantly to the increase in TFP efficiency. The 
technology change index showed a slight decline at 0.994 , which is a decrease of $0.6 \%$ and plays a major role in reducing TFP efficiency. The pure technical efficiency change index value was 1.003 , indicating an average annual growth of $0.3 \%$. The scale efficiency change index was 1.001 , indicating an average annual growth of $0.1 \%$. On an annual basis, only in the periods of 2010 to 2012, 2014 to 2015, and 2016 to 2017 did the TFP of China's health care services increase, while all other years showed a decline in TFP. From 2010 to 2011, technical efficiency increased by $1 \%$, TC by $0.8 \%$, pure technical efficiency by $0.2 \%$, and scale efficiency by $0.8 \%$, with technical EC being the main reason for increased TFP (Table 2).

\section{Changes in health care service delivery efficiency across various regions}

From 2009 to 2018, TFP showed an upward trend in 12 provinces: Beijing, Tianjin, Shanxi, Liaoning, Jilin, Shanghai, Jiangsu, Zhejiang, Hubei, Guangdong, Shaanxi, Xinjiang, and Tianjin. Among these provinces, Shanghai, Beijing, and Tianjin showed the fastest increase in TFP. At their peak, they achieved increases of $7 \%, 4.2 \%$, and $3.8 \%$, respectively. Shandong's TFP remained unchanged at a value of 1 . Simultaneously, the TFP in 18 provinces showed a downward trend, with Ningxia, Shaanxi, Qinghai, and Sichuan showing the largest decreases, reaching $2.5 \%, 2.4 \%$, and $2.1 \%$, respectively. Overall, the efficiency of health care delivery in most parts of the country had declined, but not by much. From 2009 to 2018, the technical efficiency, pure technical efficiency, and scale efficiency of health service delivery values in Chinese provinces were greater than 1; however, their technical progress values were less than 1. Specifically, from 2009 to 2018, only seven Chinese provinces had a 
technical progress value of 1 for their health care service delivery. These seven provinces are Beijing, Tianjin, Shanghai, Jiangsu, Zhejiang, Guangdong, and Hubei. The other 24 provinces achieved a score of less than 1. China's efforts to improve provincial health care service delivery efficiency mainly arise from the fact that the promotion of technical progress is necessary for maintaining an appropriate scale of health care investment and improving its management (Table 3).

\section{Comparison of regional efficiency differences}

Between 2009 and 2018, the average TFP for health care service delivery was 1.006 in East China, 0.997 in Central China, and 0.989 in Western China. Overall, East China ranked at the top, followed by Central China, then Western China. Health care service delivery efficiency in East China has been rising despite year to year fluctuations, mainly due to the rapid increase in technical progress. In contrast, Western China needs to strengthen its ability to manage health care service delivery and improve pure technical efficiency. Central China has seen a slower growth of technical scale efficiency; they should further develop health care service delivery, improve the allocation of health care resources, and improve their scale efficiency through technological and management improvements. Meanwhile, technical progress in East, Central, and Western China all show a declining trend, indicating that technical progress is the main constraint on improving health care service delivery efficiency, as shown in Table 4. The data also reveals that these regions should improve their efficiency and development capacity through technological and management improvements (Table 3). 


\section{Analysis of the factors influencing China's health care service delivery efficiency}

There is a positive correlation between the efficiency of health care service delivery and bed occupancy rate, the percentage of people with tertiary education attainment, gross regional domestic product (GRDP), the percentage of health care expenditure, and the percentage of primary care visits. There is a negative correlation between the efficiency of health care service delivery and the average length of hospital stays, as shown in Table 4.

\section{Discussion}

Based on the panel data of 31 provinces and cities in China from 2009 to 2018, the DEA-BCC model and the Malmquist index method were used to measure the efficiency of health care service delivery in each locality. The Tobit regression model was used to analyze the factors influencing efficiency improvements, and draws the following conclusions.

From the static efficiency calculation of medical and health service supply, the overall efficiency of health care service delivery in China's 31 provinces and municipalities was relatively high, with an average combined efficiency of 0.965 . Twenty-one provinces, including Beijing, Tianjin, Shanghai, and Zhejiang, had a combined efficiency value of 1, which was at the production frontier. The other ten provinces were in a state of varying degrees of inefficiency, mainly due to their low pure technical efficiency and scale efficiency values. For regions where scale efficiency values were less than 1 and had diminishing returns to scale, careful regional health planning should be carried out to optimize the allocation of health care resources and prevented the overexpansion of various components of the health care service system. With overexpansion, it becomes difficult to achieve effective 
coordination, thus reducing delivery efficiency. Meanwhile, the government should fully

implement its supervisory and management responsibilities to reasonably control the scale of health care resource investments, and avoid undesirable outcomes such as the waste of health care resources due to blind expansion of health care institutions, declining resource allocation efficiency, and a decline in the quality of health care service delivery. If the government carries out these responsibilities, it would effectively improve the overall efficiency of China's health care service delivery system.

The Malmquist index of China's health care service delivery efficiency from 2009 to 2018 was 0.998 , of which the Malmquist index of TFP efficiency in 13 provinces, including

Beijing, Tianjin, Shanghai and Jiangsu, was greater than 1. The Malmquist index of TFP efficiency in 18 other provinces, including Ningxia, Shaanxi, Qinghai, and Sichuan, was less than 1. At the regional level, the efficiency of health care service delivery in East China increased, while the TFP efficiency of health care services in Central and Western China decreased. To address the imbalance of regional health care service delivery efficiency, the government should formulate health development plans suitable for each region based on their actual conditions, optimize the health care resource allocation structure, and gradually resolve the conflict between shortage and waste of health care resources so as to improve such resource allocation in a targeted manner.

Simultaneously, the government should integrate various high-quality management models, improve the management and operational decision-making efficiency of medical institutions, strictly control unreasonable expansion of bed space and personnel, optimize resource allocation, improve the operational efficiency of health care service delivery, and build a 
high-quality and efficient health care service delivery system. The Tobit regression analysis revealed that the tertiary education attainment factor was significant, passed the 0.01 level test. GRDP and health care expenditures are also significant, passed the 0.05 level test, which were important factors in improving the TFP efficiency of health care services. The correlation coefficient between the average length of hospital stays and TFP efficiency is negative; thus, they were negatively correlated, meaning they hinder the improvement of TFP efficiency. Additionally, the bed occupancy rate, the average length of hospital stays, and the percentage of primary care visits have an impact on improving efficiency, albeit not significantly. Therefore, to further improve the efficiency of health care service delivery, it is necessary to increase regional economic development and educational attainment, increase health care expenditure, further reduce the average length of hospital stays, and increase bed occupancy rates.

\section{Conclusions}

This study found disparities in health care service delivery efficiency among various provinces, and that most provinces could still improve in terms of pure technical efficiency and scale efficiency to varying degrees. A dynamic analysis based on the Malmquist index reveals that the TFP efficiency of health care service delivery among Chinese provinces is in decline. From the spatial distribution perspective, changes in health care service delivery efficiency across regions vary greatly. From the efficiency growth perspective, East China shows the largest amount of growth, followed by Central China then Western China. In addition, the factors of tertiary education attainment, GRDP, and health care expenditures 
show a significant influence on improving health care service delivery efficiency.

\section{Abbreviations}

BCC: Banker-Charnes-Cooper; DEA: Data envelopment analysis; DMU: Decision-making unit; EC: Efficiency change; GRDP: Gross regional domestic product; OLS: Ordinary least squares; TC: Technical change; TFP: Total factor productivity

\section{Declarations}

\section{Availability of data and materials}

The datasets used and/or analysed during the current study are available from the corresponding author on reasonable request.E-mail: yjwz87@163.com.

\section{Ethics approval and consent to participate}

The study protocol was approved by the ethical review committee of The First Affiliated

Hospital of Anhui Medical University.

\section{Consent for publication}

306 Not applicable.

\section{Availability of data and materials}

308 Please contact the corresponding author for data requests.

\section{Competing interests}

310 The authors declare that they have no competing interests.

\section{$311 \quad$ Funding}

312 This study was supported by the National Social Science Foundation of China(19CGL061).

\section{Authors' contributions}


314 All authors have contributed to the conception and formulation of this article. Kui Chen

315 drafted the first version of the manuscript, Jun Ye regarding the methodological and statistical

316 examination.

\section{Authors' details}

$318{ }^{1}$ Kui Chen, The First Affiliated Hospital of Anhui Medical University. ${ }^{2}$ Jun Ye,Department of

319 Public Management, School of Public Health and Management, Wenzhou Medical

320 University.

\section{Acknowledgements}

$322 \mathrm{XXX}$ 


\section{References}

325 [1]SHUO TAO L. Research on public health service supply system of Chinese medical [J].

326 Journal of Wuzhou University, 2016,5 (26) : 10-16.

[2] MENG L, SHUYAN G, SIPING D. Measurement of hospital efficiency and total factor productivity in China based on Bootstrap-Malmquist-DEA Correction [J]. Health economics research, 2019,36 (3) : 63-68.

[3] WANGCHUN C, GUANGMING L. Journal of Nanjing University of traditional Chinese medicine (social science edition), 2015,16 (3) : 180-185.

[4] Bo W, Lin Y. Effective supply of medical and health resources under the concept of shared development: based on comparison between urban and rural areas [J]. Dongyue review, $2017,38(9): 156-166$.

[5] WENJUAN W. Research on medical service equity in the context of Chinese new medical reform [J]. Journal of People University of China, 2016,30 (2) : 93-100. medical institutions in various regions of China [J].Chinese hospital management, 2016,36 (5) : 32-34.

[8] YUCHEN Y, YUE X , NAN X, et al. Study on efficiency of Tertiary public Traditional

[6] Data Envelopment Analysis_-Let the Data Speak for Thenselves[M].Joe Zhu.2016.02.

[7] SISI K, XINHUI L, CHANGGENG L. Analysis of deA-Malmquist efficiency index of Chinese medicine hospitals in China based on DeA-Malmquist index [J].Chinese health resources, 2019,22 (6) : 435-439. 
[9] FANGRAN D, WEI C, YUNYAN F, et al. Study on Malmquist index of operational

345 efficiency of third-level Traditional Chinese medicine hospitals in Beijing [J].Chinese

346 hospital management,2016,36(7):55-57.

[10] ZONGWU W, FANGRAN D, CHENCHENG M, et al. Study on the operational

efficiency of second-level traditional Chinese medicine hospitals in Beijing based on

Malmquist index [J].Chinese hospital management,2016,36(10):50-52.

[11]CAVES D W,CHRISTENSEN L R,DIEWERT W E.The economic theory of index

numbers and the measurement of input,output and productivity

J1.Econometrica,1982(6):1393-1414.

[12]FARE R,GROSSKOPF S,SORRIS M.Productivity growth,technical progress and

efficiency change in industrialized coun-trieslj.American economic review,1994(5):66-83.

[13]TOBIN J Estimation of relationships for limited dependent variables.

Econometrics,1958(1):24-36.

[14] National Health Commission, PRC. China Health Statistics Yearbook [M]. Beijing:

China Union Medical University Press,2019.

[15]National Bureau of Statistics of the People's Republic of China.China Social Statistics

Yearbook [M]. Beijing: China Statistics Press,2019.

[16] JUXIANG C,YINGJING Li .Evaluation of operational efficiency of third-level first-class 
364 [17] HONGWEN J, XUEMIN L. Research on household Credit Efficiency and influencing

365 factors in Gansu Province -- An empirical Analysis based on DeA-Malmquist Index and Tobit

366 Model [J].Journal of Lanzhou University of finance and economics, 2019,35 (4):10-21.

367 


\begin{tabular}{|c|c|c|c|c|c|c|c|c|}
\hline \multirow{4}{*}{ Provinces } & \multicolumn{4}{|c|}{2009} & \multicolumn{4}{|c|}{2018} \\
\hline & Overall & Pure & Scale & Returns & Overall & Pure & Scale & Returns \\
\hline & efficiency & technical & efficiency & to scale & efficiency & technical & efficiency & to scale \\
\hline & & efficiency & & & & efficiency & & \\
\hline Beijing & 0.912 & 0.915 & 0.996 & irs & 1 & 1 & 1 & - \\
\hline Tianjin & 1 & 1 & 1 & - & 1 & 1 & 1 & - \\
\hline Hebei & 1 & 1 & 1 & - & 1 & 1 & 1 & - \\
\hline Shanxi & 0.643 & 0.734 & 0.876 & $\mathrm{drs}$ & 0.847 & 0.85 & 0.996 & drs \\
\hline $\begin{array}{l}\text { Inner } \\
\text { Mongolia }\end{array}$ & 0.767 & 0.778 & 0.986 & drs & 0.808 & 0.813 & 0.993 & drs \\
\hline Liaoning & 0.71 & 0.923 & 0.769 & drs & 0.822 & 0.876 & 0.939 & drs \\
\hline Jilin & 0.721 & 0.806 & 0.894 & drs & 0.764 & 1 & 0.764 & drs \\
\hline Heilongjiang & 0.921 & 0.949 & 0.971 & drs & 0.916 & 1 & 0.916 & drs \\
\hline Shanghai & 1 & 1 & 1 & - & 1 & 1 & 1 & - \\
\hline Jiangsu & 0.923 & 1 & 0.923 & $\mathrm{drs}$ & 0.901 & 1 & 0.901 & drs \\
\hline Zhejiang & 1 & 1 & 1 & - & 1 & 1 & 1 & - \\
\hline Anhui & 0.96 & 1 & 0.96 & drs & 0.96 & 0.965 & 0.994 & drs \\
\hline Fujian & 1 & 1 & 1 & - & 0.974 & 0.976 & 0.998 & drs \\
\hline Jiangxi & 1 & 1 & 1 & - & 1 & 1 & 1 & - \\
\hline Shandong & 0.907 & 1 & 0.907 & drs & 0.97 & 1 & 0.97 & drs \\
\hline Henan & 1 & 1 & 1 & - & 1 & 1 & 1 & - \\
\hline Hubei & 0.911 & 0.941 & 0.969 & drs & 1 & 1 & 1 & - \\
\hline Hunan & 0.968 & 0.997 & 0.97 & $\mathrm{drs}$ & 1 & 1 & 1 & - \\
\hline Guangdong & 1 & 1 & 1 & - & 1 & 1 & 1 & - \\
\hline Guangxi & 1 & 1 & 1 & - & 1 & 1 & 1 & - \\
\hline Hainan & 1 & 1 & 1 & - & 1 & 1 & 1 & - \\
\hline Chongqing & 1 & 1 & 1 & - & 1 & 1 & 1 & - \\
\hline Sichuan & 1 & 1 & 1 & - & 1 & 1 & 1 & - \\
\hline Guizhou & 1 & 1 & 1 & - & 1 & 1 & 1 & - \\
\hline Yunnan & 0.997 & 1 & 0.997 & drs & 1 & 1 & 1 & - \\
\hline Tibet & 1 & 1 & 1 & - & 1 & 1 & 1 & - \\
\hline Shaanxi & 0.927 & 0.953 & 0.973 & $\mathrm{drs}$ & 1 & 1 & 1 & - \\
\hline Gansu & 0.891 & 0.922 & 0.967 & $\mathrm{drs}$ & 1 & 1 & 1 & - \\
\hline Qinghai & 1 & 1 & 1 & - & 1 & 1 & 1 & - \\
\hline Ningxia & 1 & 1 & 1 & - & 1 & 1 & 1 & - \\
\hline Xinjiang & 0.824 & 0.826 & 0.998 & $\mathrm{drs}$ & 0.967 & 0.981 & 0.986 & irs \\
\hline Mean & 0.935 & 0.959 & 0.973 & & 0.965 & 0.983 & 0.982 & \\
\hline
\end{tabular}


Table 2.Malmquist index of health care service delivery between 2009 and 2019 in China

\begin{tabular}{cccccc} 
Year & $\begin{array}{c}\text { Technical } \\
\text { efficiency }\end{array}$ & $\begin{array}{c}\text { Technical } \\
\text { progress }\end{array}$ & $\begin{array}{c}\text { Pure technical } \\
\text { efficiency }\end{array}$ & $\begin{array}{c}\text { Scale } \\
\text { efficiency }\end{array}$ & $\begin{array}{c}\text { Total factor } \\
\text { productivity }\end{array}$ \\
\hline $2009-2010$ & 0.995 & 0.988 & 0.99 & 1.004 & 0.982 \\
$2010-2011$ & 1.01 & 1.008 & 1.002 & 1.008 & 1.019 \\
$2011-2012$ & 1.005 & 1.005 & 1.012 & 0.993 & 1.011 \\
$2012-2013$ & 0.995 & 0.986 & 1.003 & 0.993 & 0.981 \\
$2013-2014$ & 1.005 & 0.981 & 1.002 & 1.003 & 0.986 \\
$2014-2015$ & 1.005 & 1 & 1.007 & 0.998 & 1.005 \\
$2015-2016$ & 1.012 & 0.977 & 1.008 & 1.004 & 0.989 \\
$2016-2017$ & 1.001 & 1.016 & 0.998 & 1.003 & 1.017 \\
$2017-2018$ & 1.007 & 0.988 & 1.005 & 1.003 & 0.995 \\
Mean & 1.004 & 0.994 & 1.003 & 1.001 & 0.998 \\
\hline
\end{tabular}


376 Table 3.Malmquist index of health care service delivery between 2009 and 2019 in 31 provinces of 377 China

\begin{tabular}{|c|c|c|c|c|c|}
\hline Provinces & $\begin{array}{l}\text { Technical } \\
\text { efficiency }\end{array}$ & $\begin{array}{l}\text { Technical } \\
\text { progress }\end{array}$ & $\begin{array}{l}\text { Pure technical } \\
\text { efficiency }\end{array}$ & $\begin{array}{l}\text { Scale } \\
\text { efficiency }\end{array}$ & $\begin{array}{l}\text { Total factor } \\
\text { productivity }\end{array}$ \\
\hline Beijing & 1.01 & 1.031 & 1.01 & 1 & 1.042 \\
\hline Tianjin & 1 & 1.038 & 1 & 1 & 1.038 \\
\hline Hebei & 1 & 0.991 & 1 & 1 & 0.991 \\
\hline Shanxi & 1.031 & 0.988 & 1.016 & 1.014 & 1.019 \\
\hline $\begin{array}{l}\text { Inner } \\
\text { Mongolia }\end{array}$ & 1.006 & 0.991 & 1.005 & 1.001 & 0.997 \\
\hline Liaoning & 1.016 & 0.99 & 0.994 & 1.022 & 1.006 \\
\hline Jilin & 1.006 & 0.995 & 1.024 & 0.983 & 1.001 \\
\hline Heilongjiang & 0.999 & 0.993 & 1.006 & 0.994 & 0.992 \\
\hline Shanghai & 1 & 1.07 & 1 & 1 & 1.07 \\
\hline Jiangsu & 0.997 & 1.01 & 1 & 0.997 & 1.007 \\
\hline Zhejiang & 1 & 1.019 & 1 & 1 & 1.019 \\
\hline Anhui & 1 & 0.999 & 0.996 & 1.004 & 0.999 \\
\hline Fujian & 0.997 & 0.991 & 0.997 & 1 & 0.988 \\
\hline Jiangxi & 1 & 0.986 & 1 & 1 & 0.986 \\
\hline Shandong & 1.008 & 0.993 & 1 & 1.008 & 1 \\
\hline Henan & 1 & 0.987 & 1 & 1 & 0.987 \\
\hline Hubei & 1.01 & 1 & 1.007 & 1.004 & 1.01 \\
\hline Hunan & 1.004 & 0.987 & 1 & 1.003 & 0.991 \\
\hline Guangdong & 1 & 1.001 & 1 & 1 & 1.001 \\
\hline Guangxi & 1 & 0.983 & 1 & 1 & 0.983 \\
\hline Hainan & 1 & 0.986 & 1 & 1 & 0.986 \\
\hline Chongqing & 1 & 0.985 & 1 & 1 & 0.985 \\
\hline Sichuan & 1 & 0.979 & 1 & 1 & 0.979 \\
\hline Guizhou & 1 & 0.976 & 1 & 1 & 0.976 \\
\hline Yunan & 1 & 0.996 & 1 & 1 & 0.996 \\
\hline Tibei & 1 & 0.948 & 1 & 1 & 0.948 \\
\hline Shaanxi & 1.008 & 0.998 & 1.005 & 1.003 & 1.007 \\
\hline Gansu & 1.013 & 0.985 & 1.009 & 1.004 & 0.997 \\
\hline Qinghai & 1 & 0.979 & 1 & 1 & 0.979 \\
\hline Ningxia & 1 & 0.975 & 1 & 1 & 0.975 \\
\hline Xinjiang & 1.018 & 0.986 & 1.019 & 0.999 & 1.004 \\
\hline Eastern China & 1.005 & 1.001 & 1.004 & 1.001 & 1.006 \\
\hline Central China & 1.002 & 0.994 & 1.003 & 0.999 & 0.997 \\
\hline Western China & 1.003 & 0.987 & 1.003 & 1 & 0.989 \\
\hline National mean & 1.004 & 0.994 & 1.003 & 1.001 & 0.998 \\
\hline
\end{tabular}


Table 4.Tobit regression analysis of the factors associated with health care service delivery

\begin{tabular}{|c|c|c|c|c|}
\hline Variables & $\boldsymbol{\beta}$ & $S E$ & $t$ & P value \\
\hline Bed occupancy rate & 0.0006143 & 0.0004025 & 1.53 & 0.140 \\
\hline $\begin{array}{l}\text { Average length of } \\
\text { hospital stays }\end{array}$ & -0.003986 & 0.0034255 & -1.16 & 0.256 \\
\hline $\begin{array}{l}\text { Associate's degree or } \\
\text { above }\end{array}$ & 0.002656 & 0.0007571 & 3.51 & 0.002 \\
\hline $\begin{array}{l}\text { Gross regional domestic } \\
\text { product }\end{array}$ & $3.30 \mathrm{e}-07$ & $1.48 \mathrm{e}-07$ & 2.23 & 0.035 \\
\hline $\begin{array}{l}\text { The percentage of health } \\
\text { care expenditure }\end{array}$ & 0.002869 & 0.0010623 & 2.70 & 0.012 \\
\hline $\begin{array}{l}\text { The percentage of } \\
\text { primary care visits }\end{array}$ & 0.0264599 & 0.0534739 & 0.67 & 0.509 \\
\hline
\end{tabular}




\section{Supplementary Files}

This is a list of supplementary files associated with this preprint. Click to download.

- TobitData.xls

- DEAData.xIs 